\title{
Review of Issues of Language Assessments for Non-native Speakers of English
}

\author{
Abigail Ayiglo Kuwornu \\ University of Professional Studies, Accra (UPSA)
}

\begin{abstract}
The paper reviews issues in language assessment, especially pertaining to the challenges faced in examining non-native speakers of English. The review revealed that low proficiency levels of well-established standard varieties of English affect the test achievement of non-native speakers across the world. Furthermore, the absence and improper evaluation of English tests, coupled with poor educational systems in Africa, Asia, and the Caribbean lead to very low achievement in English. Based on the review, the paper recommends the use of accommodation, culture-specific designed tests, and more research as remedy for the problems. Areas of future research for Africa and specifically, Ghana are recommended.
\end{abstract}

Keywords: language assessment, ESL, assessment evaluation, accommodation

\section{Introduction}

The status of English as the most widely used and important lingua franca for global and international communication is not in doubt. The international status of English as the language of global mobility also means there are a lot of people who speak English as their second language (L2). As a result of its international status, more and more countries are putting emphasis on an "English" education to gain acceptance and to create more opportunities for its people on a global market that thrives on English. However, language is not the only key to accessing these global opportunities - Knowledge and skills are equally important. One of the most conventional ways to acquire the knowledge and skills is through formal education. With formal education comes its key measuring tool-assessment. Assessment is conducted in a language that is "foreign" to L2 English speakers. The result is that L2 speakers do not enter the "global competition" with L1 English speakers on an equal footing partly because of the language factor in assessment. Thus, the crust of this paper is to present a review of the issues of language assessment confronting L2 speakers of English. The review also aims at bringing out some of the solution(s) used in dealing with L2 language assessment issues. Lastly, gaps in the literature are identified with the aim of encouraging language assessment research, especially in Ghana.

\section{The English Language Learner}

The English Language Learner (ELL) is defined as a learner who is "still developing proficiency in English"

Abigail Ayiglo Kuwornu, Ph.D. candidate, Department of Public Relations Management, University of Professional Studies, Accra (UPSA). 
(Educational Testing Service, 2009, p. 1). Wolf et al. (2008) explained that it used to characterise students who have a degree of difficulty in speaking, reading, writing, and understanding English. Another related term used in the literature (Abedi, Hofstetter, \& Lord) is students with Limited English Proficiency (LEP). Artiles, Rueda, Salazar, and Higareda (2005) considered ELLs as cases for special education and should be treated as such. They claimed, however, that in the US, this is usually not the case because most ELLs belong to minority groups located in poor districts which lack the needed infrastructure to provide them with the needed attention.

\section{Issues of ELLs and High Stakes Tests Achievement}

Two of the commonest, if not the commonest, international high stakes test are the International English Language Testing System (IELTS) and the Test of English as a Foreign Language (TOEFL). While IELTS is developed by the British Council mainly for Australian and British Universities, TOEFL is an American test developed by American and Educational Testing Service, Princeton, New Jersey mainly for North American Universities (Davies, Hamp-Lyons, \& Kemp, 2003). According to Arcuino (2013), there is no significant difference between final GPA (Grade Point Average) of students who are admitted to either of the two tests. According to Templer (2002), standardised test such as IELTS and TOEFL test used to determine English language achievement in language for admission to Western universities for ELLs in developing economies lacks equity. One of the reasons he argued accounts for the disparity in the use of the exams is that they are generally too expensive for ELLs in these economies to afford and, as a result, only favours the rich who can afford them. $\mathrm{He}$ also argued that the difference in the cultures of ELLs in these second language economies differs from the tester's culture and thus, negatively influences the results of the test. He cited the electronic nature of the tests as another indicator of the lack of equity because test takers may not be used to a computerised system. This may affect their confidence. Also, it secludes a large number of computer illiterates from taking the test. Arcuino (2013) confirmed that older people did not perform well on computer-based international tests as a result of their low proficiency in computer skills. Butler and Stevens (2001) also emphasized the inequity of high stakes test for ELLs. This is because in some schools, students are made to mix with the high proficient students and it becomes the teacher's job to attend to the special need of the ELL. Politicians and the public underestimate issues of validity concerning how ELL students are treated in high stakes tests. Although these concerns are warranted, I believe that any ELLs interested in studying abroad must also learn good proficiency skill in English and the use of computer. This is because these skills are among the key indicators in their overall achievement in school especially in a technological world of today.

Furthermore, Templer (2002) raised another important factor regarding the variety of English used in tests. He contended that more often than not, it is the American variety that is used in testing students. Some may argue that if one wants access to American education, then one needs to be understood by the teachers who teach them. However, the problem with such an argument is that it loses view of the fact that universities have an international output with regards to both faculty and students. This does not derail the fact that Western universities need to have benchmark for determining the quality of students who can attend their universities. However, measuring such standards with high stakes test can be problematic especially when the same cut-off points are used for both native and non-native speakers of English. A more forward approach is the acceptance of high school language qualification in English from the home country. On the students' arrival to the university, remedial proficiency 
courses can be recommended to a student where it is deemed necessary. In addition, another important point which Templar fails to mention is that more and more universities are exempting students who have had a substantial part of their education taught in English from having to pass high stakes international English proficiency test.

The issue about what variety of English to use in English tests is, also, contentious (Davies et al., 2003). Canagarajah (2006) emphasized that the debate surrounding how English should be assessed internationally is demonstrated by two positions: World Englishes (WE) position and Standardised English position. The WE positions argue for the inclusion of varieties Englishes spoken in non-native English language countries around the world. On the contrary, the Standardised English position opts for the use of commonly accepted varieties of English spoken native English countries like Britain and the US. Hamid (2014) analyzed test-takers views on the inclusion of World English norms in international English tests. Although most of the respondents were L2 speakers of English, they strongly rejected the proposal on the bases that it will greatly affect the equity and standardisation of the international tests. According to Hamid, the results seem striking, looking at the fact the respondents spoke varieties of World Englishes themselves. Based on earlier studies, Hamid described such characteristics as "linguistic schizophrenia" which is caused factors such as "linguistic self-denial" and "linguistic idealism" (Hamid, 2014, p. 273). Davies et al. (2003) also added that there is a general uncertainty about which variety of English to use in international language test. According to them, the difference between acceptable varieties of English (like the British and America) seems to be quite small (Davies et al., 2003).

Furthermore, the perception that living abroad can enhance achievement in language tests may be misconstrued (GU, 2014). GU observed that students with year abroad experience and those who did but have the experience achieved equal results in their language test in an analysis of TOEFL results. GU found out that the length of time spent studying positively correlated with language achievement rather than the length of time spent in an English speaking country. This result may be a pointer that ELLs in both native and non-native English speaking communities may have similar characteristics if they have had similar duration in studying English.

According to Solano-Flores and Trumbull (2003), the existing testing approaches to language testing lacked validity and equity because they overlooked the complexities of the language and cultural background of students. They contended that $9.3 \%$ of students in American pre-schools are L2 speakers of English and this negatively affects their performance in their test achievement. For instance, a test constructed with a culture new to the test-taker affects the comprehension and interpretation of the text. However, he admitted that if every test has to be set within a culture, it may be impossible. He, thus, recommended that tests should be given to students with different cultural backgrounds in English and their own native language. However, it is not clear how a test which is originally in English can be given in another language and can be devoid of the English cultural constructs. For that to be accomplished, these cultural constructs may be translated into the native language of the test taker. This in itself presents a huge setback because one of the difficulty things to translate is cultural-specific constructs. If not well done, the test in the students L1 may be different from that of English one and that can affect the standardisation of the test, a fact that Solano-Flores and Trumbull (2003) admitted. They also pointed out that their suggestions can be particularly difficult to implement in situations when students have so many varying language and cultural backgrounds. 
Solano-Flores and Trumbull (2003) mentioned that another difficulty L2 speakers face comes as a result of difference in culture of their L1 and English is the difficulty the evaluator faces in understanding them. They argued that raters of L2 speakers may misinterpret responses of the L2 speaker because and consequently, this will negatively impact on performance and achievement of the L2 speaker. Educational Testing Service (2009) of America has emphasized the need the fairness and validity of assessment is important in improving the equity in opportunity for minority language groups.

In addition, according to Williams and Pike (2014), British West Indian Caribbean (BWIC) is misclassified as English speaking students in the US although majority of them are from other languages and other varieties of English. The result is that they do not receive extra help in the school system and this affects their achievement rates. In their study, they realised that teachers were aware of this development. They, thus, called on districts to acknowledge the need of BWIC and the subsequent institution of remedial programmes for them.

\section{English Tests in Non-native English Countries}

One may think that these issues regarding ELLs may not be applied to L2 English learning communities where almost all test takers are non-native English speakers. However, taking such a stance may be misleading because there are growing numbers of English L1 speakers in Africa and Asia urban centres as opposed to their rural counterparts who may lack adequate proficiency by the time they are out of basic schools. Both categories of students are expected to write the same external exams without recourse to the differences in their proficiency levels and language backgrounds. In a study carried out in South Africa, Howie, Venter and Surette (2008) concluded the correlation between native language proficiency and English proficiency is very high. In South Africa, teachers used code switching to accommodate students who are not proficient enough. Although most assessment researchers will find this as positive, the writers see the practice as negative as it does not help with the fast acquisition of English.

For instance, Worrell (2004) reported that the curriculum does not reflect the relationship between language and culture and calls for a restructuring of a curriculum including the language one to reflect the diverse cultural background of students in Trinidad and Tobago. Worrell bemoaned how the curriculum has served external interest rather than the internal need of Trinidad and Tobago.

Ramanathan (2008) bemoaned the ineffectiveness of language of language assessment for Kindergarten to Grade 12 in India. She pointed out that, for instance, the four language skills are not assessed equally. In fact, speaking and listening, she mentioned, are hardly assessed. Ramanathan (2008) also called for the legitimization of Indian English. Lam (2015) also asserted that most teachers in Hong Kong lacked adequate skills and knowledge of language assessment. Lam, thus, concluded that there is a huge gap between theory and practice. Abioye (2010) lamented that generally teachers in Nigeria lack knowledge of new skills in testing and the general levels of English proficiency are largely low. According to the Abioye (2010), a test is capable of assessing both the teacher's and the learner's levels of proficiency. In Nigeria, ineffective implementation of English curriculum was seen as a major cause of the poor performance of students in high school external exams (Tom-Lawyer, 2014). According to Nkechi (2008), it is important to regularly appraise language assessment to ensure that they serve the changing needs of society. Nkechi outlined some of the problems associated with language assessment in Nigeria including emphasis on one assessment for the admission into institutions of higher learning, mismatch 
between curriculum and tests, limited time allotted to marking, and lack of political will. Dery and Andy-Lamptey (2006, p. 3) opined that there is a low rate of reliability of assessment scores of students' continuous assessment in Ghanaian basic and high schools. In all the schools they selected for their study, the mean scores of students' continuous assessment presented to the West Africa Examinations Council (WAEC), the main assessor of basic and high school external examinations, were higher than the mean scores in the external exams. They attributed the problem to the inability of teachers to use a systematic approach to assess students which is as a result of their lack of training in assessment. In most cases, they argued that the teachers were too generous in allotting marks for students' continuous assessment. As a result of the low reliability of the continuous assessment, a formula is used to moderate continuous assessment results to ensure equity. However, in my opinion, such a test could be also very problematic because what WAEC may be characterised as generous scores may actually be the true reflection of students' performance and the relatively lower scores in the WAEC's exams may be as result of issues concerning standardisation of the WAEC exams. For instance, a factor such as anxiety, as mentioned earlier, can affect the results of students' scores. In an external exam, anxiety levels could be relatively higher and may negatively affect the scores of students. Mireku, Amedahe, and Etsey (2005), in a study that involved 1,063 trained teachers and untrained teachers, reported that in Ghana, the qualification of teachers was generally low and teachers also lacked the adequate resources for teaching. Furthermore, teachers found it difficult to teach certain topics like mechanical writing. Also, the results showed that a third of English teachers teach only half of the entire syllables. Topics related to oral English were hardly treated.

Ross (2008) is a conglomeration of testing papers in Asia. In India, large scale indirect testing has resulted in negative washback of languages tests. In Thailand, there are efforts to change grammar based-tests to communicative-based ones. In spite of changes in Hong Kong's language in education policy from Mandarin to Chinese, the teaching of English tests has increased in Hong Kong's schools. In Japan, as a result of high number of universities with low population size, universities are forced to abandon English language requirements for interviews or recommendations from high school principals. However, Haggerty and Fox (2015) testified to the positive influence of high stake tests in teaching and learning. In a study carried by examining middle school students in South Africa, high stake tests were seen to have increased the preparation time among middle school students and the longer students had prepared for the test, the more motivated they were to take the test. They also observed that of the bars set for achievement in high stakes test are too high and they create unrealistic expectations which lead to frustration.

Wilmut and Yakasai (2006), in their assessment of student achievement in three Nigerian States (Kaduna, Kano, and Kwara) revealed that generally, there was a low performance in English (and Mathematics). They argued that as a result of large class sizes, most teachers resorted to simple recall question for easy assessment. This has resulted in rote learning. The result is that the higher cognitive skills of students are not assessed.

Acheoah (2014) examined the principles that affected the assessment of Nigerian Senior School Certificate Examination (SSCE). Acheoah conducted two levels of evaluation — one at the program level and the other at the student level. Furthermore, Acheoah enumerated a number of causes leading to low performance levels in Nigerian high school. To begin with, he argued that there was a disparity between Nigerian English, the everyday language the children use and British language, the language of examination. Furthermore, he complained about the use of sub-standard English in teaching. Also, he added that most teachers of English are not involved in the 
final assessment of their students and that there was a need for them to have access to the Chief Examiners' report so they can apply it to their teaching. They also recommend that since education is the main tool for measuring proficiency, there is a need to revamp the educational system to improve proficiency in English. Much as the results of this research is not different from the case of many other second English speaking countries in Africa, the nature that the research is carried out makes some of the findings questionable. For instance, the use of 20 scripts for an analysis of a nation-wide exam for a period ranging from 2009 to 2013 is inadequate. Secondly, the methodology of the paper is difficult to understand as Acheoah reported "we do not propose strictly scientific method for the study of administering questionnaire we [choose] an integrative discursive approach" (p. 3). This information is the only information about the methodology: It is quite scant and vague.

According to the 2013 National Education Assessment (NEA) report of assessment in basic schools in Ghana which was published in 2014, there is a need to improve the teaching of English schools. In their report, it was evident that achievement in English is correlated with achievement in Mathematics. They claim these two subjects, though very important to the overall achievement in school, recorded the worst performance. According to the NEA (2014), there is a huge disparity in performance between pupils in urban Ghana and rural Ghana. For instance in English, they report that while 59.2\% reached an appreciable proficiency level in the rural areas, only $27.1 \%$ did so in the rural areas. From the reports, even the performance in urban areas has serious implication for the teaching of English in basic level. This is because they complain that about less that $2 \%$ average could read English fluently with comprehension. The critical issue that arises from these figures is why students with very low proficiency levels in English continue to be tested in English, a language they cannot read and comprehend. Abedi (2002) lamented that, generally, ELLs have low language achievement rates.

\section{Dealing With L2 Assessment Language Difficulties}

Communicative language teaching (CLT) and tests. Canagarajah (2006) suggested that it important that test needs to move from assessing the grammatical competence of test-takers to assessing the communicative competence of test-takers. He mentioned that communicative competence can assess language competence in the areas of knowledge of communicative repertoire, negotiation, and language awareness. Gonzalez (1996) also emphasized the need for communicative language test. Some of the characteristics of a communication its performance based, that is, it is interactive and language assignments are scored on real life situations. Fulcher (2000), however, warned that it is difficult to administer communicative tests on a large scale. HU (2002), outlined some challenges of communicative approaches of language testing. To begin with, teachers have not been trained and slowly accept communicative test norms. HU explained that is also because communicative language teaching norms contradicts Chinese culture of learning which is more orderly in nature. Another hindrance to using more novel approaches to teaching contradicts the Chinese expectations of education as means of acquiring both intellectual and moral training — an ideology which draws inspiration from Confucian thinking.

Accommodation. The term is a borrowed concept from the field of education of disability students used to characterize the extra attention to make up for their learning disabilities (Butler \& Stevens, 2001). Abedi et al. (2004) defined accommodation as the inclusion strategies used during assessments to provide equal opportunities for learners with low proficiency levels. These opportunities, they added, may involve modifying the test itself or the procedure of the test taking. The concept is a widely acceptable one and in the United States and it is backed 
by a public act, No Child Left Behind (NCLB). The fact that first language does affect English learning is problematic that this is not considered in the selecting who is qualified to be accommodated. According to the ETS (2010, p. 4) it is pointed out that based on the NCLB act, we can differentiate between modification and accommodation. It defined accommodation as "any change in standardised testing conditions intended to make test more fair and accessible for any individual or subgroup that does not change the construct being changed". According to Butler and Stevens (2001), any form of support that helps test-takers them comprehend a text in English so that they can demonstrate what they know is accommodation. It is added that it may extend the time allowed for the test, adding extra materials and equipment or even changing the way the test itself is presented. Conversely, modification as any change to the standardised testing condition that does not change the construct is mentioned (ETS, 2009, p. 5). From its explanation, it seems that the difference between accommodation and modification is that the former is used mainly to improve the performance of minority subgroup as a minority language group. They also mentioned a third related term, variation, which they defined as the test a cover term that includes accommodation and modification, used to refer to any changes in a standardised test. Wolf et al. (2008) reduced linguistic complexity that does not change the construct of the test item and changed the settings - for instance from a big group to a small - are also types of accommodations strategies used. They posited that the commonest accommodation used is the provision of bilingual dictionaries, glossaries, and word list during the test. However, Butler and Stevens (2001, p. 413) saw modification as sub-type of accommodation. They drew attention to the two types of accommodation: "modification to the test itself" and "modification of test procedure". On the one hand, they cited the use of the native language, modification of test direction, and the provision of extra examples illustrations of modifications to a test itself. On the other hand, they cited breaks during exams, reading out questions in English and providing oral directions in native language as examples of modification to the test. Butler and Stevens also mentioned accommodation is not static. For instance, as the student becomes more proficient, the accommodation provided also changes. Therefore, they recommended that there need be more research work to determine the appropriate timing when a student no longer needs accommodation. They also recommended the need for more studies to determine how equity can be maintained in a test where some students receive accommodation.

Criteria for accommodation. Abedi et al. (2004) mentioned that the eligibility criteria for accommodation in America are stated specific. Among the most common criterion used is the level of proficiency in English and the least common is the native language of students and students' academic knowledge in their native languages. According to Plough and Briggs (2004), in the study to investigate the effectives of the evaluation criteria used in determining proficiency in American universities, they concluded the use of listening comprehension and pronunciation tends to be the most important indicators in determining proficiency.

According to the ETS (2009, p. 6), accommodation becomes necessary when they are different in the proficiency levels in English. It is added that the decision to change the language of testing should be also dependent on the degree proficiency in the native language. This is because, not all test takers may be literate in their native language. For instance, in most developing countries where English is used as a second language, many lack literacy in their native language.

There is no one best fit accommodation strategy that fits all test situations. Thus, Abedi, Hofstetter and 
Baker (2000, p. 17) cautioned against the use of "a one-fits-all accommodation option for all situations".

Wolf et al. (2008) mentioned that the law accommodation for English and Mathematics test for students from grades 3 and 8 and at least more less that the first year of high school. Abedi et al. (2004) complained that although sometimes there is a clear case that students should be considered for accommodation, it is done because it may not be logistically feasible. Although, proficiency has been used to generally determine the need for accommodation in language testing, Maclytryre (1997) reported that anxiety can also affect the results of L2 testing. He mentioned that students with relatively higher levels of anxiety underestimated their competencies and those with lower levels of anxiety overestimated their competencies, and in both cases, the scores of the test takers were negatively affected. Therefore, it is important that test takers can be helped to adequately deal with anxiety before or during the exams to ensure equity of a test. In a study conducted using Japanese, English students in universities, accommodation was used to test performance in an oral test. Mihara (2015) reported the use of three types of accommodation. The formats used included giving the oral question just once in both the students' L1 and in English, giving the question in both written and oral version in English, and giving the question in only the L1. According to Mihara, the changes in test formats did not yield any significant difference in the performance of students. This is perhaps because although, students may have been aided through the provision of alternatives question in their L1 and written forms, they, generally, have lacked adequate understanding of the test questions which were in English. Thus, irrespective of the type of accommodation strategies used, if a student lacks adequate comprehension of the test items, accommodation will still provide negative results.

Solano-Flores and Trumbull (2003) suggested that two versions of the test—one in English and one in the L1 - should be administered. They argue that the test should be administered simultaneously during different periods and the results of the test be treated. Their suggestion is, however, unclear. For instance, it is not clear whether the test taker should take both versions of the test. Neither is it clear whether both versions will be used to evaluate the test taker. If the English is allowed to take the test in the most preferred language, it, also, lends itself to a lot of difficulties. For instance, if the language of instruction is different from the language of the test, there is no equity between the test of native speakers and that of the ELLs. If the student has to take both versions of the test, then equity of the test becomes questionable because the native speaker will be expected to write only one test. Butler and Stevens (2001) also mentioned that there are two options for providing assessment in native language: translating the English assessment and developing a parallel assessment. He added that the latter is more preferable. Much as accommodation by way of the use of the ELL's native language is laudable, its usage in many African countries will be problematic because many African are equally illiterate in their native languages.

Accommodation and validity. Abedi et al. (2004) argued that the use of criteria for determining qualification for accommodation is quite problematic because since professional judgement is used to determine eligibility for accommodation, the evaluator's level of knowledge and previous experience in testing is key.

Another validity problem with using the students' native language as testing instead of English can call the test to question. This is because this removes the uniformity that is expected between the language of testing and evaluation. Abedi $(2004$, p. 7 ) emphasized this point when they argued that although it is important to maintain the language of testing and the language of instruction, this key determinant is ignored. If a student qualifies for the use of his native language in an exam, then that student should have been taught his or her native language 
since comprehension is compromised at the time of time. There seems to be no point examining people in a language they feel comfortable when there was not consideration in the choice of language used in teaching them.

According to Abedi et al. (2000), a valid accommodation is one that helps the target but does not affect the scores of other students. This means it should be capable of improving the performance of students to classify ELL and LEP because of their handicap, but it should not be beneficial to the native speakers. Therefore, they questioned the use of extra time as an accommodation strategy because although it provides more time for EELs to comprehend the time, it gives undue advantage to the native speakers, thus, negatively affecting the validity of the results.

The perception that the administration or two different tests in two different languages question the equity of the test is backed by little research (Ong \& Sereci, 2008). Balanced bilinguals can be used to test the varying difficulty so as to make the necessary adjustment in a test.

\section{Hope of ELL Language Testing}

Casillas and Robbins (2005) agreed that adapting a test to the culture of the test-takers is very important. As a way of improving the standards of international language teaching and assessment, the Cambridge English Language Assessment, a non-for-profit off-shoot of the Cambridge University provides custom-made country by country curriculum and assessment to L2 English countries (Carrier \& Khalif, 2014). Such services have been available in Europe, the Middle East, Asia, and Latin America. According to Carrier and Khalif (2014), because the tests are country specific, their curriculum is designed to meet the English language needs of the country as well as meeting international standards. For these reasons, they yield better results that the one all fit ones like the IELTS. In China, where Cambridge curricula and testing was introduced in 2009, according to Carrier and Khalif, there has been an improvement in language competency. Also, there has been an increase in confidence and motivation among teachers.

In spite of its importance and the fact that Africa has a lot of English speakers, the researchers made no mention of its use in Africa. According to Carrier and Khalif, a lot of research and funding go into developing the curricula and test for a country. Perhaps, if the cost of building the test is passed on the test-taker and with the low income rate in Africa, the developers are handicapped or not motivated to do so in Africa. The inference that can be drawn from Carrier and Khalif is that the Cambridge test may address the issue of culture irrelevance of IELTS and TOEFL. However, it does not address the issues of accessibility and cost.

ZHENG and CHENG's (2008) study analysed the proficiency level of College English Test (CET) of undergraduates Chinese students who majored in courses other than English. The study found out that the CET suited the Chinese context. Also, the test had different variation to suit the different undergraduate major courses. Thus, the course has resulted in a positive washback effect that promoted the teaching and learning of English at the undergraduate level in Chinese universities. Once again, we see that when a test is specifically built to suit the cultural backgrounds of the test-takers, it works.

In a study to analyze the perception of students, it was reviewed that assessments mirrored teaching (CHENG, WU, \& LIU, 2015). This result is not surprising looking at the fact that the assessor was the same as the teacher. However, it was also, revealed that students were not involved in the assessment criteria and students were also held solely responsible for learning. 
Although Harding, Alderson and Brunfaut (2015) asserted that listening is the most under-researched of the language skills based on empirical research and he proposed a diagnostic test to be used for analyzing second language listening. They pointed out the test must reflect the norms of second language learners.

Stephens (2004) argued that the use of a formative approach to writing a syllable for the Advanced Caribbean Examination has resulted in a syllable which is culturally relevant and fits all groups and students. He pointed out that formation is largely consultative in nature, involves all stakeholders, and thus, usually, serves their purposes.

Gonzalez (1996, p. 21) argued that in any test, it is important that the tester reduces the "test anxiety". Gonzalez was of the view sometimes, students' familiarity with venues and test administrator can affect the performance.

\section{Recommendations for Future Research}

The literature of language assessment in general seems to be focused more on America. Majority of the studies available examine the curriculum in general and in effect evaluate how classroom assessment meets the requirements of the curriculum. There is a need of research that evaluates high stake tests such as those organised by the West Africa Examination Council (WAEC). It will be interesting to know how the principles of evaluation relate to these tests. Furthermore, research in the use of accommodation in the classroom and for high stake tests in Africa, especially Ghana, may reveal contradicting or similar trends will be on interest to "accommodation" research.

\section{Conclusion}

According to Abedi et al. (2000), language is important, in not only assessing language courses, but also content courses. They reiterated that, for instance, English is important for learning of context courses and that there was a correlation between proficiency in English and performance in Mathematics. In spite of its importance, language in education is usually neglected (Howie et al., 2008), especially for second language speakers. As evident from the literature, accommodation, communicative language teaching and testing, and the adaptation of course syllable to the culture of test takers can improve language assessment for ELLs. It is, therefore, important that all stakeholders invest the needed funding, training, and research into language assessment issues. Ghana may lead the way for Africa if these suggestions are followed. In the absence of these remedies and others that may not have been covered by the literature reviewed, the future of English in Ghana and Africa as a whole seems gloomy owing to the large number of minority language groups who have limited access to quality language (English) education.

\section{References}

Abedi, J. (2002). Standardized achievement tests and English language learners: Psychometric issues. Educational Assessment, 8(3), 231-257.

Abedi, J. (2004). The No Child Left Behind act and English language learners: Assessment and accountability issues. Educational Researcher, 33(1), 4-14.

Abedi, J., Hofstetter, C. H., \& Lord, C. (2004). Assessment accommodations for English language Learners: Implications for policy-based empirical research. Review of Educational Research, 74(1), 1-28.

Abedi, J., Lord, C., Hofstetter, C. H., \& Baker, E. (2000). Impact of accommodation. Strategies on English language learners' test 
performance. Educational Measurement: Issues and Practice, 19(3), 16-26.

Abioye, T. (2010). Managing language testing in Nigerian large classes: Processes and prospects. English Language Teaching, 3(2), $82-87$.

Acheoah, J. E. (2014). Ordinary level English in Nigeria: On assessment and failure. International Journal of English Language, Literature and Translation Studies, 1(2), 1-5. Retrieved from www.ijelr.in/vol.Issue.2.2014.htm

Arcuino, C. L. T. (2013). The relationship between the test of English as a foreign language (TOEFL), the international English language testing system (IELTS) scores and academic success of international master's students (Ph.D. thesis, Colorado State University Fort Collins, Colorado).

Artiles, A. J., Rueda, R., Salazar, J. J., \& Ignacio, H. (2005). Within-group diversity in minority disproportionate representation: English language learners in urban school districts. Exceptional Children, 71(3), 283-300.

Brown, D. H., \& Abeywinkrama, P. (2010). Language assessment: Principles and classroom practice (2nd Edition). New York: Pearson Education.

Butler, F. A., \& Stevens, R. (2001). Standardized assessment of content knowledge of English language learners K-12: Current trends and old dilemmas. Language Testing, 18(4), 409-427.

Canagarajah, S. (2006). Changing communicative needs, revised assessment objectives: Testing English as an international language. Language Assessment Quarterly, 3(3), 229-242.

Carrier, M., \& Khalif, H. (2014). Cambridge English: Case studies. Cambridge: Cambridge English Assessment, Cambridge University.

Casillas, A., \& Robbins, S. B. (2005). Test adaptation and cross-cultural assessment from a business perspective: Issues and recommendations. International Journal of Testing, 5(1), 5-21.

CHENG, L. Y., WU, Y. F., \& LIU, X. Q. (2015). Chinese university students' perceptions of assessment tasks and classroom assessment environment. Language Testing in Asia, 5(13), 1-17. Retrieved from http://dx.doi.org/10.1186/s40468-015-0020-6

Davies, A., Hamp-Lyons, L., \& Kemp, C. (2003). Whose norms? International proficiency test in English. World Englishes, 22(4), 571-584.

Dery, R. G., \& Addy-Lamptey, W. (2006). Effects of classroom assessment scores on the final scores used in grading students at senior high school in Ghana. A report for the West African Examination Council.

Educational Testing Service. (2009). Guidelines for the assessment of English language learners. A guideline by the Educational Testing Service, USA.

Fulcher, G. (2000). The communicative legacy in language testing. System, 28, 483-497.

Gonzalez, A. B. (1996). Testing English as a foreign language: An overview of methodological considerations. RESLA, 11, 17-49.

GU, L. (2014). At the interface between language testing and second language acquisition: Language ability and context of learning. Language Testing, 31(1), 111-133.

Haggerty, J. F., \& Fox, J. (2015). Raising the bar: Language testing experience and second language motivation among South Korean young adolescents. Language Testing in Asia, 5(11), 1-16, Retrieved from http://dx.doi.org/10.1186/s40468-015-0018-0

Hamid, M. O. (2014). World Englishes in international proficiency tests. World Englishes, 33(2), 263-277.

Harding, L., Alderson, C. J., \& Brunfaut, T. (2015). Diagnostic assessment of reading and listening in a second or foreign language: Elaborating on diagnostic principles. Language Testing, Special Issue, 32(3), 1-20.

Howie, S., Venter, E., \& Surette, van S. (2008). The relationship between English second language proficiency and mother tongue in non-native English speakers in South Africa. Paper presented at The International Research Conference of the International Association for the Evaluation of Educational Achievement, Taipei, Taiwan.

HU, G. (2002). Potential cultural resistance to pedagogical imports: The case of communicative language teaching in China. Language, Culture and Curriculum, 15(2), 93-105.

Lam, R. (2015). Language assessment training in Hong Kong: Implications for language assessment literacy. Language Testing, 32(2), 169-197.

MacIntyre, P. D., Noel, K. A., \& Clement, R. (1997). Biases in self-ratings of second language proficiency: The role of language anxiety. Language Learning, 47(2), 265-287.

Mihara, K. (2015). An analysis of the differences among L2 listening comprehension test formats. Language Testing in Asia, 5(12), 1-16. Retrieved from http://dx.doi.org/10.1186/s40468-015-0021-5

Mireku, K. D., Amedahe, F. K., \& Etsey, K. (2005). Opportunity to learn English and Mathematics in Ghanaian primary schools. A report of a study conducted on behalf of Ghana Education Service, Curriculum Research and Development Division (CRDD) 
to facilitate the Basic Education Comprehensive Assessment System (BECAS).

National Education Assessment Unit. (2014). Ghana 2013 national education assessment technical report. Ghana: Education Service, Ministry of Education.

Nkechi, M. C. (2008). Social and educational impact of language assessment in Nigeria. Nordic Journal of African Studies, 17(3), 198-210.

Ong, S. L., \& Sireci, S. G. (2008). Using bilingual students to link and evaluate different language versions of an exam. US-China Education Review, 5(11), 37-46.

Plough, I. C., \& Briggs, S. L. (2004). A multi-method analysis of evaluation criteria used to assess the speaking proficiency of graduate student instructors. Review of Educational Research, 74(1), 1-28.

Ramanathan, H. (2008). Testing of English in India: A developing concept. Language Testing, 25(1), 111-126.

Ross, S. J. (2008). Special issue language testing in Asia: Evolution, innovation, and policy challenges. Language Testing, 25(1), $5-13$.

Solano-Flores, G., \& Trumbull, E. (2003). Examining language in context: The need for new research and practice paradigms in the testing of English-language learners. Educational Researcher, 32(2), 3-13.

Stephens, C. (2004). Formative approaches to constructing syllabuses for the Caribbean advanced proficiency examinations. Caribbean Curriculum, 11, 115-128.

Templer, B. (2002). High-stakes testing at high fees: Notes and queries on the international English proficiency assessment. Critical Education Policy, 2(1), 189-256.

Tom-Lawyer, O. (2014). An evaluation of the English language curriculum of the Nigeria certificate in education: A case study of a college of education. Open Journal of Social Sciences, 2, 69-79.

Williams-Pike, E. P. (2014). School leaders' perceptions of Caribbean students' English language needs (Ph.D. thesis, Walden University).

Wilmut, J., \& Yakasai, M. I. (2006). A brief review of the assessment of student achievement in Kaduna, Kano and Kwara states of Nigeria. A report prepared to the DfID/World Bank SESP preparation mission.

Wolf, M. K., KAO, J., Herman, J., Bachman, L., Bailey, A., Bachman, P. L., Farnsworth, T., \& CHANG, S. M. (2008). Issues in assessing English language learners: English language proficiency measures and accommodation uses. Los Angeles: A Practice Review by National Center for Research on Evaluation, Standards, and Student Testing (CRESST), University of California. Retrieved from http://files.eric.ed.gov/fulltext/ED502283.pdf

Worrell, P. (2004). Addressing cultural diversity in a Creole space: The SEMP language arts curriculum. Caribbean Curriculum, 11, $1-22$.

ZHENG, Y., \& CHENG, L. (2008). Test review: College English test (CET) in China. Language Testing, 25, 408-417. 